\title{
A la búsqueda de un canon literario mexicano: de El Recreo de las Familias a El Renacimiento
}

Andreas Kurz

Universidad de Guanajuato

\section{Resumen}

El siguiente trabajo presenta los esfuerzos de las revistas culturales mexicanas del siglo XIX en la búsqueda de un canon literario propio. Dicha empresa fue muy complicada, en primer lugar por la situación política inestable del país, así como por la constante indecisión sobre qué influencias aceptar y cuáles rechazar. La elección final se vio determinada en buena medida por motivos políticos, lo cual no la hace menos valiosa.

Palabras clave: canon, Recreo de las familias, El Renacimiento, Ignacio Manuel Altamirano, influencia.

\section{Abstract}

The next work presents the efforts of the mexican cultural publications in the search of their own literary canon. This venture was very complicated, in the first place because of the politic inestability in the country, as well as the constant indecisition of which influence take and which one reject. The final choice was principally determined by politic reasons, which does not make it less valuable.

Keywords: canon, Recreo de las familias, El Renacimiento, Ignacio Manuel Altamirano, influence. 
A raíz de la independencia política mexicana, los escritores del país es decir, procuran alcanzar, como correlato de la autonomía política, la independencia cultural. Sin embargo, durante varias décadas el canon literario mexicano permanecerá como ilusión. Hay, a partir de los intentos del cubano José María de Heredia, una serie de proyectos periodísticos, de revistas más o menos culturales, de corta vida casi todas, que pretenden formular en sus páginas el canon, encontrar un lugar para la literatura mexicana dentro de las letras europeas, sin que sea, al mismo tiempo, un vástago algo exótico de la literatura española. ${ }^{1}$ Sin embargo, dichos proyectos fracasan, sobre todo, debido a la inestable situación política del país y a las diversas intromisiones extranjeras que, una y otra vez, obligan a los escritores a reformular sus posiciones ante las culturas ajenas, la francesa y española en primer lugar.

Un ejemplo típico, entre muchos, para este fracaso inicial constituye El Recreo de las Familias, revista publicada por Ignacio Rodríguez Galván entre noviembre de 1837 y abril de 1838. Aparecieron 12 números con un volumen de 42 páginas cada uno. Se deduce claramente de la introducción programática del miembro de la Academia de San Juan de Letrán que El Recreo había sido concebido como un proyecto cultural nacional:

En medio de este movimiento, de esta revolución, de este incendio, cada megicano desea tener una parte, aunque sea pequeña, en el engrandecimiento de su nacion; porque están persuadidos de que cada ciudadano debe hacer lo que pueda a favor de su pais, sin cuidarse de que sus compatriotas hagan lo mismo que él, ó que permanezcan

${ }^{1}$ Los índices preparados por Miguel Ángel Castro y Guadalupe Curiel (ver bibliografía) ofrecen un panorama exhaustivo de los proyectos periodísticos del siglo XIX mexicano. Sin embargo, el estudio que aclare convincentemente el impacto de las publicaciones culturales en el contexto político aún no se ha escrito. 
en vergonzosa inaccion. Unicamente de esta manera podremos desmentir algun dia, llenos de placer y de orgullo, á esas naciones que nos deprimen sin conocernos; que olvidando los dias de su infancia, solo se acuerdan de su actual poder, y que debian avergonzarse al contemplar lo que fueron en las circunstancias en que nosotros nos hallamos (El Recreo: 2). ${ }^{2}$

Es obvio que "esas naciones que nos deprimen" son, en primer lugar, el antiguo amo, Espańa, y la nueva fuerza colonial, Francia, aunque al mismo tiempo se insinúa el creciente poder político y económico de Estados Unidos que, por otro lado, carece de importancia en el ámbito cultural.

Rodríguez Galván pretende “nacionalizar” su revista, reducir el número de las aportaciones extranjeras y publicar casi exclusivamente a autores mexicanos. Propósito ilusorio, absurdo hasta cierto grado, como un muy somero análisis del contenido de El Recreo demuestra. Artículos de revistas europeas que, como es la práctica de la época, se reeditan sin indicación de sus orígenes forman la base cuantitativa de la revista. Sobre todo El Artista, revista española que es, por su parte, una imitación de L'Artiste parisino, resultó ser una fuente de artículos casi inagotable. ${ }^{3}$ Una publicación española, que toma como modelo a una revista francesa, presta textos a la revista mexicana que se auto-proclama como nacional. Esta constelación algo esquizofrénica es típica para la situación de las letras mexicanas durante las primeras décadas de la frágil autonomía política. Alejandro Rivas juzga al res-

${ }^{2}$ No corrijo la ortografía y acentuación arbitrarias de El Recreo. Reflejan el intento de distanciarse, también en este ámbito, de España. Es frecuente el uso del ustedes en lugar del vosotros, no hay imitación ortográfica del ceceo peninsular y se procura imitar los fonemas efectivamente usados en México. Sólo pocos años después tales intentos se percibirán como barbarismos.

${ }^{3}$ Son significativos los datos de vida de las tres publicaciones. L'Artiste: 73 años, El Artista: año y medio, El Recreo: medio año. 
pecto de El Renacimiento, de Altamirano, que "la literatura tiene un valor fundamentalmente político, por sus posibilidades en el terreno pedagógico y didáctico" (157). Esta afirmación vale igualmente para las publicaciones anteriores a El Renacimiento, sin embargo, hay que agregar que no sólo se trata de una función pedagógica y didáctica intrínseca a la literatura, sino que su valor político se genera también mediante la simple selección que obtiene, de este modo, un matiz simbólico.

Es imposible llenar las páginas de El Recreo sólo con autores mexicanos; sigue siendo necesario recurrir a la producción europea. La selección, entonces, predetermina el canon nacional aún inalcanzable, a la vez que marca antipatías y simpatías políticas. El mecanismo se ilustra con el texto "Cómicos franceses en España” inserto en el tercer número de la revista. Se trata de una crónica de Jules Edouard Alboise du Pujol (1805-1854), exitoso autor del teatro de bulevar de su época. Pujol relata las experiencias de una compañía de teatro francesa durante una gira por Espańa y subraya, sobre todo, el comportamiento grotesco y el mal gusto de los espectadores ibéricos que "se complacen con los largos dramas, con las innumerables variaciones, con los desafíos, y sobre todo, con los bailes voluptuosos de su patria. Cuando las piezas que se representan no agradan al público, en los entreactos hacen bailar el bolero y el fandango" (El Recreo, 111). Sobra decir que Rodríguez Galván no escoge este texto por su calidad literaria, sino porque puede ilustrar con él la supuesta arrogancia francesa ante culturas ajenas. En otras palabras: si hay que escoger entre Espańa y Francia, entre el antiguo enemigo y la nueva amenaza, entonces las simpatías de los editores mexicanos se encuentran, a pesar de todo, del lado español, que sufre el mismo menosprecio que Rodríguez Galván había criticado en su introducción a la revista. El comentario del traductor del texto de Pujol no podría ser más claro al respecto: "Es lo peor que puede tener Madrid, lo que por desgracia 
va teniendo nuestro país: bueno es que imitemos de los estrangeros lo útil; pero costumbres y modas que el clima ó la educacion exigen únicamente, parece necedad imitar de quien quiera que sean" (112). Se vislumbra la idea de la "madre patria” España con la que México se solidariza culturalmente en tiempos difíciles, aunque a diferencia de la crisis de 1898, el oponente, en este caso, es un país "latino" y no los bárbaros anglosajones. Se relativiza el multicitado "afrancesamiento" del siglo XIX mexicano y se revela una oposición decidida contra la influencia avasalladora de lengua y cultura francesas en México.

El Recreo no ofrece ninguna discusión seria acerca de las nuevas tendencias románticas de la literatura francesa. Aparte de textos muy cortos sólo imprime la traducción del poema "Pensée des morts", de Lamartine, así como —en el número seis — un retrato biográfico del joven Victor Hugo. ${ }^{4}$ Abundan, por otro lado, textos de las letras peninsulares ${ }^{5} \mathrm{y}$, sorprendentemente, textos de la literatura alemana superan cuantitativamente a los franceses. Se encuentran textos cortos de Goethe, reflexiones estéticas de Winckelmann y un fragmento de una tragedia de Tieck. ${ }^{6}$

Aunque estas aportaciones son préstamos de revistas europeas, sí constituyen una novedad en México: el intento de encontrar una

${ }^{4}$ Se trata de un estudio del influyente crítico y novelista Jules Janin (1804-1874) publicado originalmente en la primera edición del Dictionnaire de la Conversation, de 1832. Janin elogia al poeta Hugo, pero rechaza tajantemente al dramaturgo. Para El Recreo, Hugo aún no puede ser el ídolo literario que será para la generación de Altamirano y, todavía, para los modernistas.

${ }^{5}$ Eugenio de Ochoa (1815-1872), precursor conservador del romanticismo español, es uno de los autores más representativos en El Recreo. Sus aportaciones se tomaron de El Artista, cuyo fundador y editor fue Ochoa junto con Federico de Madrazo (Shaw, 54).

${ }^{6}$ Se trata de algunos fragmentos de Leben und Tod der heiligen Genoveva (Vida y muerte de Santa Genoveva) traducidos del francés por Rodríguez Galván como Genoveva de Brabante (El Recreo: 426-435). 
alternativa a la literatura francesa como modelo omnipresente para una literatura nacional mexicana; el aún tímido experimento con una literatura no románica que podría dar una pauta para la elaboración del canon nacional. Rodríguez Galván admite en su despedida que los objetivos originales del Recreo fracasaron. No ha sido capaz de generar el canon anhelado. Mas este fracaso no se debe a la falta de escritores y pensadores mexicanos, sino a la falta de tiempo, dinero y suscriptores: "Tambien se hubieran publicado muchos artículos originales, y relativos á nuestra nacion; pero nada de esto podemos efectuar: con vergüenza lo decimos, nuestros compatriotas no nos han ayudado en esta empresa [...]" (El Recreo: 474s.). No hay ni apoyo material, ni moral, el canon proyectado se limita al "hubiera", pero el camino ya se trazó, parece decir el joven poeta y narrador. El canon mexicano sólo se encontrará si se define la posición de la literatura mexicana ante y en medio de la española y la francesa. Tal exigencia implica una postura político-histórica clara; por un lado, la necesidad de aumentar y diversificar las lecturas extranjeras, por otro, 30 años después del cierre de El Recreo de las Familias, El Renacimiento de Ignacio Manuel Altamirano retoma esa táctica y la sistematiza.

No sorprende que a sólo dos años del final de la intervención francesa y la ejecución de Maximiliano de Habsburgo, las posturas anti-francesas se hayan acentuado en El Renacimiento. Tampoco sorprende que Altamirano dé cabida en su revista no sólo a autores liberales, la mayoría de ellos sobrevivientes del romántico Liceo de Hidalgo, sino también a escritores, historiadores y pensadores declaradamente conservadores. No en balde uno de los autores más publicados por El Renacimiento es José María Roa Bárcena, quien rechazó un cargo en el gabinete de Maximiliano porque éste había defendido posiciones demasiado liberales (Muñoz Fernández, t. 2: 616ss).

Altamirano buscaba en las páginas de su revista una reconciliación política a escala nacional que se debía, como demuestra Alejan- 
dro Rivas, más a la convicción de que ciertas tendencias políticas ya no constituía ningún peligro, que a un verdadero espíritu neutro ( $\mathrm{Ri}$ vas, passim). Sin embargo, esta pseudo-reconciliación no se extiende a Francia. En su famoso artículo introductorio, Altamirano explica el retraso de las letras mexicanas con dos argumentos divergentes: 1) Una parte de los escritores mexicanos fue absorbida por los acontecimientos bélicos. 2) Otra parte se dejó esclavizar por la cultura francesa: "los demás discípulos de las musas habían colgado sus liras de los sauces extranjeros, ó las habían arrojado para empeñar el sable. Hondo silencio reinaba en la república de las letras" (El Renacimiento, I: 4). ${ }^{7}$ No cabe duda de que estos "sauces extranjeros" habían crecido sobre todo en Francia. Altamirano aclara este punto poco después con expresiones casi idénticas a las usadas por Rodríguez Galván en su introducción a El Recreo de las Familias. El objetivo principal de El Renacimiento es "vindicar á nuestra querida patria de la acusación de barbárie con que han pretendido infamarla los escritores franceses, que en su rabioso despecho quieren deturpar al noble pueblo á quien no pudieron vencer los ejércitos de su nación" (5). ${ }^{8}$ No es difícil encontrar bajo la superficie del chovinismo nacionalista - entendible, por otro lado, en las circunstancias de 1869- el intento de relativizar el valor desmedido otorgado a la cultura francesa a lo largo del siglo XIX. Intento nada nuevo si pensamos en El Recreo y otras publicaciones culturales, como la hermosa serie de El Año Nuevo. ${ }^{9} \mathrm{Al}-$

${ }^{7}$ Cito de la edición facsimilar preparada por la UNAM. Se presenta en un volumen, mas se marca la cesura constituida por la venta de la revista, a mediados del año 1869, a su impresor, la que produce dos épocas en miniatura.

${ }^{8}$ Como se puede observar El Renacimiento sigue, aunque de forma más moderada, la ortografía rebelde de El Recreo.

${ }^{9}$ Los cuatro tomos aparecieron entre 1837 y 1840, preparados por la imprenta Galván, cuyo propietario fue un tío de Rodríguez Galván. Se incluyeron sobre todo textos de una generación vagamente "romántica" de las letras mexicanas alrededor de la Academia de San Juan de Letrán. Hay edición facsimilar preparada por la UNAM (ver: referencias bibliográficas). 
tamirano subraya que su revista debe ser una publicación puramente cultural que excluye la lucha política. Sin embargo, la citada declaración de guerra a la cultura francesa puede leerse, y debe leerse, como una afirmación de carácter político. De esta manera, los fenómenos culturales de la época obtienen una función claramente politizada; la guerra "cultural" reemplaza a las contiendas militares y diplomáticas; la búsqueda de un canon literario nacional es, al mismo tiempo, una toma de posición ante la cultura occidental: la literatura mexicana como integrante de la literatura occidental, pero no necesariamente limitada a su parte "latina". Se puede decir, retrospectivamente, que pocos años después, con el surgimiento de ideas irracionales alrededor de latinidad e hispanidad, se perderá una gran oportunidad para la literatura mexicana — quizás hispanoamericana en general— que se había ofrecido en las páginas de El Renacimiento.

Desde su primera crónica, del 2 de enero de 1869, Altamirano insiste en la necesidad de diversificar las referencias culturales dominantes en México. ${ }^{10}$ Respecto a ciertas costumbres de año nuevo escribe:

La costumbre francesa $[\ldots]$ de hacerse regalos [...] no se ha naturalizado en nuestro país, lo mismo que la de hacerse visitas y de besar á los conocidos, lo cual será muy bello, pero nunca podrá aceptarse, y menos con los recuerdos que dejó aquella guerra de invasión, que nunca se borrarán de nuestra memoria. / Nosotros seguimos la costumbre española, que es también la inglesa y la alemana. ( $E l$ Renacimiento: 7)

${ }^{10}$ Se puede apuntar de paso que Altamirano renueva el género de la crónica en México. Se trata de textos que bajo una apariencia trivial — bodas, bautizos, acontecimientos sociales frívolos - esconden una discusión de temas políticos y culturales de relevancia. La discusión de temas literarios predomina, mas el texto literario se ve claramente como un producto de una sociedad y un tiempo específicos. 
Una extrańa alianza con Inglaterra y Alemania contra Francia se establece como receta para encontrar la propia posición en medio de la cultura occidental.

La estadística, por lo menos en este caso, dice más que el análisis detallado de las aportaciones a El Renacimiento. De los 550 textos que forman el total de la revista sólo ocho provienen de autores franceses: cuatro poemas de Victor Hugo traducidos por Isabel Prieto (en los números 7 y 8 del primer tomo, y 11 del segundo); una traducción libre de "Le Poète", de Alfred de Musset, a cargo de Manuel M. Flores (primer tomo, número 27); “Graziella”, una versión española de "Le premier regret", de Lamartine, encargada a Roa Bárcena (I: 214s.); una traducción de "Le lac" por Ricardo Ituarte (primer tomo, número 11) y una traducción de una crónica de Eugène Cortet, con la que Altamirano sustituye una de sus crónicas (I: 173-176). Hugo, Musset, Lamartine y un autor efímero desprovisto de interés literario: a esto se reduce el papel de la literatura francesa en las páginas de $E l$ Renacimiento: tres autores consagrados, que se perciben como valores universales, y un desconocido. No hay huella de los movimientos innovadores que, a partir de mediados del siglo, cambian el rumbo de las letras europeas: nada de Baudelaire, cuyas Flores del mal habían aparecido 12 ańos antes del primer número de la revista mexicana, nada de parnasianismo o simbolismo.

La actitud de la revista ante las nuevas tendencias se resume en un artículo necrológico a Lamartine publicado por el joven Justo Sierra. No puede negarse, según Sierra, la decadencia de las letras francesas:

Una gran esterilidad literaria es el carácter distintivo en Francia, de la generación que ha sucedido á aquella que en otra época hacía estremecer al mundo con las estrofas sublimes de Hugo, llorar con los melancólicos cantares de Lamartine y reir de placer con los versos alegres y voluptuosos de Musset, el Beranger del gran mundo. (El Renacimiento: 333) 
Sierra, cuya información proviene casi exclusivamente de las críticas de Jules Janin en el Journal des Débats, se encarga de la discusión alrededor de la literatura francesa. Dos artículos extensos sobre Hugo y Lamartine, así como un esbozo histórico comprimido de la literatura francesa, dan testimonio de esta tarea. El análisis de los artículos de Sierra da, no obstante, el mismo resultado que la estadística: dos o tres poetas olímpicos universales y mucha decadencia. Paul Bénichou interpreta el concepto del "gran hombre" como típico para la fase temprana del romanticismo dentro de un estado laico, la veneración religiosa abolida recae sobre ellos (Bénichou). Sin embargo, es difícil imaginarse, a pesar de las reformas de Benito Juárez, que en México algunos "genios" selectos sustituyan a los santos antiguos. Los "hombres grandes", Hugo y Lamartine, fueron instituidos en primer lugar para salvaguardar una parte importante de la literatura francesa ante el trasfondo de los rencores producidos por la invasión.

Se puede contrastar este papel relativamente pobre de la literatura francesa con el otorgado a la de lengua alemana. Altamirano y sus colaboradores ofrecen las letras germanas como alternativa a la literatura francesa. José Sebastián Segura ${ }^{11}$ publica en el tercer número de la revista una introducción a la literatura alemana, la que defiende contra la predominancia de la francesa:

Entre las naciones modernas quizás no hay otra que posea un tesoro literario tan rico como Alemania [...] Nada es difícil para el germano [...] La literatura germánica no es tan popular como la francesa; porque el idioma de Schiller no es tan conocido como el de Racine. Los que ignoran la lengua alemana la tienen por bárbara, pobre é ingrata al oido. Baste decir que entre las vivas es una de las mas copiosas,

${ }^{11}$ Segura nació en Veracruz en 1822. Destacó como traductor del latín, italiano y francés. No obstante, su mayor logro son, hasta la fecha, sus traducciones de Schiller al español, con alguna seguridad las primeras versiones en el ámbito hispánico traducidas directamente del alemán. 
expresivas y elegantes. Los bardos alemanes imitan admirablemente los bellísimos metros de los griegos [...] En otra ocasion nos ocuparemos de tan interesantes trabajos, para que nuestros jóvenes literatos aumenten el caudal de su instrucción. (El Renacimiento, I: 37s.)

La asimilación de una "nueva" literatura europea se recomienda con claridad como un paso hacia la elaboración de un canon literario mexicano digno de este nombre. La labor de Segura en este contexto es decisiva. Traduce poemas de Schiller, varias de sus baladas, directamente del alemán al español. ${ }^{12}$ Produce de igual modo versiones castellanas del "Erlkönig" (Segura lo titula "El Rey de los Duendes”, I: 218s.), uno de los poemas más leídos de Goethe, así como de las parábolas religiosas del hoy olvidado Friedrich Adolf Krummacher (1767-1845). Asimismo, Rafael de Zayas ${ }^{13}$ traduce poemas de Uhland y de Ferdinand Freiligrath para la revista. ${ }^{14}$

El panorama literario de lectores y autores de El Renacimiento debe ampliarse, la unilateral veneración de la literatura francesa ha caducado. La presentación de otras literaturas, nuevas para el público mexicano, refleja, en nuestro contexto, la politización de las letras en general, de la revista de Altamirano en específico, así como la creciente confianza que Altamirano y sus colaboradores depositan en las letras mexicanas. En comparación con El Recreo disminuyen con-

12 Se trata de los siguientes poemas: "La balada de la campana" ("Das Lied von der Glocke”, I: 94-98); "El Buzo" ("Der Taucher”, I: 204s.); "El Guante” (“Der Handschuh”, I: 218); "El Caballero de Toggenburgo" ("Ritter Toggenburg”, I: 226s.); "La Joven Forastera" ("Das Mädchen aus der Fremde", I: 240); "Fantasía Fúnebre" (no identificable en alemán, I: 256s.).

13 De Zayas (1848-1932), veracruzano como Segura, vivió como diplomático en Alemania.

${ }^{14}$ Se trata de "La Maldición del Bardo" (I: 389s.), de Uhland ("Des Sängers Fluch" en alemán) y de "La Cabalgata del León” (II: 253s.), de Freiligrath (“Löwenritt”). 
siderablemente no sólo las aportaciones de autores extranjeros, de los franceses sobre todo, sino también el número de artículos procedentes de revistas españolas y francesas. Por primera vez la gran mayoría de los textos publicados es efectivamente mexicana. En consecuencia, en su despedida Altamirano puede escribir con cierta satisfacción, y con más comprensión de la realidad cultural de su país que la que había demostrado Rodríguez Galván:

El objeto á que aspiramos al fundar el RENACIMIENTO, que fué el de impulsar el progreso de la bella literatura en México, se halla completamente realizado, el movimiento literario que se nota por todas partes es verdaderamente inaudito, y al desaparecer nuestro periódico, los que hemos escrito en él, llevamos la satisfaccion, que no querrá negarnos la justicia pública, de haber contribuido empeñosamente á favorecer ese movimiento, por cuantos medios nos han sido posibles, luchando con las dificultades que en nuestro país todavía son grandes para que una empresa literaria tenga éxito, y no perdonando sacrificios, que en nuestra humilde posicion fueron de alguna cuantía. (El Renacimiento, II: 257)

El autoelogio de Altamirano es justificable. Todavía en los años 70 del siglo XIX se fundan 35 revistas de carácter predominantemente literario (Batis: XXV). En 1893, recién fallecido Altamirano, el impresor Olavarría y Ferrari impulsa la creación de una nueva revista El Renacimiento que se publicará de enero a junio de 1894 (Batis: XXVI). De esta manera, El Renacimiento, de Altamirano, se vuelve el predecesor inmediato de Revista Azul y Revista Moderna.

El canon de las letras mexicanas ha sido establecido; en las publicaciones del grupo modernista se aumentará y se pondrá a prueba mediante el continuo enfrentamiento con las tendencias más actuales e innovadoras de las letras europeas. La literatura francesa recuperará su tradicional importancia, mas, variando el postulado de Altamirano respecto a los conservadores y monárquicos, sólo porque ya no 
pueden hacer daño [...] Con y después de El Renacimiento las letras mexicanas se hallan en una posición lo suficientemente fuerte y segura de sí mismas para poder enfrentar el reto de la literatura francesa moderna. Ya no se podrá tratar de "afrancesamiento", sino de un diálogo crítico-analítico con la cultura ajena, se tratará del eclecticismo productivo característico de la literatura mestiza mexicana a partir del modernismo. El Renacimiento es el precursor decisivo en este contexto, dado que proveyó a las futuras generaciones literarias con el imprescindible canon nacional que apenas permite la internacionalización del discurso literario. La apertura de la revista de Altamirano hacia tendencias divergentes en lo ético y lo estético, la indirecta politización de las letras que podría interpretarse también como la siempre necesaria alfabetización de la política, la integración de autores "viejos" surgidos del Liceo Hidalgo y de jóvenes, como Justo Sierra, alrededor del mismo Altamirano, hicieron posible la primera formulación de un canon mexicano que sufrirá en años posteriores varias alteraciones decisivas, pero cuya existencia ya no se podrá cuestionar. La selección de autores extranjeros, casi siempre con base en criterios históricos, con base — ¿por qué no?_- en el resentimiento hacia Francia, produjo como efecto secundario no previsible y muy productivo la apertura de la cultura mexicana hacia las letras inglesas y alemanas, es decir, México se transformó en importador cultural en el sentido que André Gide da a este término: sólo el que deliberadamente se abre hacia las influencias, podrá algún día influir por su parte. Sólo la curiosidad intelectual ilimitada garantiza una producción literaria valiosa y duradera. ${ }^{15}$

${ }^{15}$ Gide formula sus ideas sobre las influencias literarias y el tráfico intercultural en una conferencia impartida el 29 de marzo de 1900 en Bruselas. La Revista Moderna la traduce y publica en julio y agosto de ese mismo año. 


\section{Bibliografía}

Batis, Huberto, "Presentación”, en El Renacimiento, pp. VII-XXVI.

Bénichou, Paul, 1981, La coronación del escritor 1750-1830, trad. Aurelio Garzón del Camino, México, FCE.

Castro, Miguel Ángel y Guadalupe Curiel, 2000, Publicaciones periódicas mexicanas del siglo XIX: 1822-1855, México, UNAM. , 2003, Publicaciones periódicas mexicanas del siglo XIX: 1856-1876, México, UNAM.

El Recreo de las Familias, 1995, edición facsimilar, México, UNAM-Instituto de Investigaciones Bibliográficas.

El Renacimiento, 1993, edición facsimilar, México, UNAM-Instituto de Investigaciones Filológicas-Coordinación de Humanidades.

El Año Nuevo 1837, 1838, 1839, 1840, 1996, edición facsimilar, 4 vols., México, UNAM.

Muñoz Fernández, Ángel, 1995, Fichero bio-bibliográfico de la literatura mexicana del siglo XIX, 2 vols., México, Factoria.

Rivas, Alejandro, 1997, "Altamirano y El Renacimiento", en Sol, Manuel y Alejandro Higashi (eds.), Homenaje a Ignacio Manuel Altamirano, Xalapa, Universidad Veracruzana (Cuadernos), pp. 153-161.

Shaw, Donald L., 1973, El siglo XIX, Historia de la literatura española, vol. 5, Barcelona, Ariel. 